\title{
ASTHMA AND ENVIRONMENTAL FACTORS IN CHILDREN
}

\author{
M. Mirzadeh ${ }^{1}$, M. Kooshesh ${ }^{2}$ and M. Mirzaei* \\ 1Department of Internal Medicine, Shahid Sadoughi University of Medical Sciences, Yazd, Iran \\ ${ }^{2}$ Tehran University of Medical Sciences, Tehran, Iran \\ ${ }^{2 *}$ Tehran University of Medical Sciences, Tehran, Iran
}

\begin{abstract}
Summary. Asthma is one of the most prevalent atopic diseases in childhood. It is characterized by inflammation of conductive airways and bronchial hyperresponsiveness. Environmental factors introduced to child in early years of life may have a protective or harmful role in developing atopic diseases. To evaluate the influence of some environmental factors such as cat or dog ownership, smoking of mother or father and environmental pollution on prevalence of wheezing in children. Subjects and methods: This was a cross sectional retrospective study. A questionnaire was designed based on International Study of Asthma and Allergies in Childhood (ISAAC). Parents of the subjects were asked to fill in the questionnaires. Children's wheezing association with keeping cats and dogs, smoking mother and father and frequency of truck passing in place of residence was investigated. 545 children were recruited in our study. Prevalence of wheezing was $9 \%$. Keeping cats in first year of life and last year was associated with less wheezing. But the latter association was not statistically significant. Keeping dogs was so scarce in area of our study, so we could not perform a rightful analysis. Frequency of truck passing was significantly higher in those with wheezing. Keeping cats in first year of life was a significant protective factor, whereas residence in an area with frequent truck passing increased wheezing in children. Results of our study can emphasize the need to keep children away from polluted areas. Further studies are needed to investigate whether keeping a pet in household can benefit children regarding all possible concerns and benefits.
\end{abstract}

Key words: asthma, wheezing, domestic cats, primary schools, environmental pollution

${ }^{\star}$ Corresponding author 


\section{INTRODUCTION}

sthma is an atopic disease with inflammation of airways leading to struc-
tural and functional changes. Severity of bronchial hyperresponsive-
ness and obstruction vary over time. Asthma affects children's quality of life and imposes a high level of burden on health care system by using available resources $[1,2]$. Asthma, in addition to having negative influence on affected individuals' life from childhood to death, may even cause harm to the next generation by complicating pregnancy [3].

Many modifiable factors can influence the presentation and course of this atopic disease. Control of these factors which range from various drugs to place of residence may have a great contribution to better asthma prevention and management $[4,5]$. Exposure to environmental allergens can lead to persistence of asthma and provoking of underlying mechanisms. Early years in life may play a more critical role for incidence of future asthma [6]. Domestic animals such as cats and dogs can be a source of allergens in house. Frequent exposure of children to pets highlights the importance of study on effect of these environmental contact [7].

Although wheezing is not found only in asthma, it is the most reasonable symptom to look for in self-report asthma. History of dyspnea induced by exercise or contact with cold air and night cough are some other symptoms suggestive of asthma [8]. Even small differences in wording of questions about wheezing may change the final results of any study [9]. So a uniform questionnaire to help compare and evaluate studies together in different parts of the world had been set up by International Study of Asthma and Allergies in Childhood (ISAAC) [10].

Industrialization process in Yazd province has resulted in increased air pollution and migration to cities. Considering lack of precise data in accordance to globally accepted questionnaires, it was necessary to estimate the prevalence of asthma and allergies with standard criteria and to try to depict the associated relation of probable risk factors. We used ISAAC standard questionnaire to estimate the prevalence of asthma and associated environmental risk factors in children aged 6-7 in Yazd.

\section{MATERIAL AND METHODS}

This cross-sectional study was carried out is Yazd province located in the center of Iran. Study group consisted of 6- to 7-year-old student population in primary school (first grade class). The number of students in Yazd region who studied in first grade was obtained from city educational officials. Considering the total number of male and female schools, 7 schools of each sex were randomly selected. In the 
selected schools, students were randomly enrolled in our study. Students' parents were invited to the school to complete the questionnaire. The questionnaire was sent to some parents who did not come to school.

Instrument for data collection in our study is based on ISAAC standard questionnaire which consists of the following parts: demographic information, a main questionnaire including questions related to wheezing and asthma and a questionnaire about environmental contacts. Collected data were analyzed with SPSS 16 statistical software for descriptive and analytic calculations. Chi square and exact fisher test were used for comparison between different groups. $P$ value of less than 0.05 was considered significant. Data of the study were analyzed anonymously and kept highly protected regarding ethical considerations.

\section{RESULTS}

This was a cross sectional retrospective study. 545 students (271 males and 274 females) aged 6-7 years were enrolled in our study: (m/f ratio: 0.99).

Prevalence of wheezing in lifetime among all children was $9 \%$ ( $\mathrm{m} / \mathrm{f}$ ratio: 3.08 ), but only $4.95 \%$ of them reported wheezing in last year. Physician diagnosed asthma was claimed by $3.3 \%$ of children ( $\mathrm{m} / \mathrm{f}$ ratio: 2.6 ). Sexual difference was statistically significant for both wheezing and physician diagnosed asthma $(p=0.001$ and $p=$ 0.05 , respectively.) Wheezing after exercise was seen in $6.6 \%$ of students ( $\mathrm{m} / \mathrm{f}$ ratio: 1.77). There was no significant difference between boys and girls regarding exercise induced wheezing.

Among those who reported no history of wheezing, $16.16 \%$ kept cat in first year of life, whereas only $6.12 \%$ of other students reported having cat in first year of life. This difference was statistically significant $(p=0.04)$. Keeping cat in last year was also more prevalent in those without wheezing, but this was not statistically significant $(p=0.09)$. Keeping dog was uncommon among families $(0.4 \%)$ and had no significant relationship with wheezing.

Smoking among mothers was not prevalent (1.1\%), but about $29 \%$ of fathers were smokers. Wheezing was more frequent seen among those with smoking father (33.3\% vs. 28.9\%), but this association was not significant $(p=0.3)$.

Frequency of truck passing in place of residence is shown in table 2. Proportion of children who claimed often or almost always truck passing was significantly higher among wheezing group $(p=0.02)$. Among children with a history of wheezing, $26.5 \%$ reported never or rarely truck passing compared to $43.0 \%$ in children without wheezing.

Asthma and environmental... 
Table 1. The frequency of wheezing in children aged 6-7 years old according to some environmental factors in Yazd Province

\begin{tabular}{|l|c|c|c|c|}
\hline Factor & $\begin{array}{c}\text { Children with a history of } \\
\text { wheezing }\end{array}$ & $\begin{array}{c}\text { Children with no history } \\
\text { of wheezing }\end{array}$ & Total & P Value \\
\hline Keeping cats in the first year of life & $6.12 \%$ & $16.16 \%$ & $15.34 \%$ & 0.04 \\
\hline Keeping cats in the past 12 months & $6.12 \%$ & $13.62 \%$ & $12.94 \%$ & 0.09 \\
\hline Keeping dogs in the first year of life & $0 \%$ & $0.8 \%$ & $0.74 \%$ & 0.68 \\
\hline Keeping dogs in the past 12 months & $0 \%$ & $0.61 \%$ & $0.56 \%$ & 0.75 \\
\hline Smoking mother & $0 \%$ & $1.21 \%$ & $1.10 \%$ & 0.56 \\
\hline Smoking father & $33.33 \%$ & $28.95 \%$ & $29.34 \%$ & 0.31 \\
\hline
\end{tabular}

Table 2. Truck passing frequency in children with and without wheezing

\begin{tabular}{|l|c|c|c|}
\hline \multicolumn{1}{|c|}{ Frequency of truck passing } & $\begin{array}{c}\text { Children with a history of } \\
\text { wheezing }\end{array}$ & Children without wheezing & Total \\
\hline Never & $5(10.2 \%)$ & $44(9.02 \%)$ & $49(9.12 \%)$ \\
Rarely & $8(16.3 \%)$ & $166(34.0 \%)$ & $174(32.4 \%)$ \\
Never or Rarely & $13(26.5 \%)$ & $210(43.0 \%)$ & $223(41.5 \%)$ \\
\hline Often & $24(49.0 \%)$ & $170(34.8 \%)$ & $194(36.1 \%)$ \\
Almost Always & $12(24.5 \%)$ & $108(22.1 \%)$ & $120(22.3 \%)$ \\
Often or Almost Always & $36(73.5 \%)$ & $278(57.0 \%)$ & $314(58.5 \%)$ \\
\hline Total & $49(100 \%)$ & $488(100 \%)$ & $537(100 \%)$ \\
\hline
\end{tabular}

\section{DISCUSSION}

Effect of environmental factors on pathways leading to asthma is a matter of concern for better management of this disease. Exposure to specific allergens during childhood may have a key role in disease establishment. School setting is a good site to investigate about asthma and its symptoms in children. Probable asthma cases in school can be detected and lead to more efficient treatment in future with taking environmental factors into account.

Respiratory symptoms and history of patients are the cornerstone of diagnosis in epidemiological studies in large populations. Wheezing is one of the best predicting symptoms for asthma in this kind of studies [11]. ISACC has made a uniform questionnaire which was the basis for our questionnaire. Before development of this international questionnaire, there was not a single set of questions for comparing asthma prevalence between different areas in the world. In the first studies to evaluate properties of this questionnaire sensitivity of $85 \%$ and specificity of $91 \%$ were reported in reply to questions about ever experiencing wheezing and wheezing in the past years. Since then, ISACC questionnaire have been used in many studies [12]. 
In our study $9 \%$ of participants reported wheezing. In a review study the prevalence of asthma symptoms in different cities of Iran is reported in the range of $2.7 \%$ to $35.4 \%$. Overall national prevalence is $13.14 \%$ [13]. This shows less prevalence of asthma symptoms in Yazd compared to national level. A wide range of current prevalence of wheeze is also observed between and within countries over time. Developed countries such UK and Australia had the highest prevalence of more than $20 \%$ whereas prevalence of less than $5 \%$ was seen in some Eastern European countries, India and Ethiopia [8, 14]. Differences observed in prevalence of asthma and asthma symptoms in different areas may be attributed to diversity in lifestyle and environmental factors in each region. In our study the prevalence of wheezing in boys was more than girls (13.65\% vs. $4.38 \%)$. This finding is consistent with results of more extended studies $[15,16]$.

Smoking father and mother was not related to wheezing significantly in our study. This seems inconsistent with other studies which report an association [17]. Several studies argued that exposure in first years of life rather than later years is the key element that can influence immunopathogenesis of asthma in childhood [18, 19]. It was suggested that upregulation of pulmonary neuroendocrine cells in relationship to mechanisms of tobacco smoke products may induce pulmonary disease. However, genetic background is what will dictate the susceptibility to environmental tobacco smoke [20]. Also smoking among mothers in our study was little. This can obscure a potential relation.

In our study keeping cats in first year of life was significantly associated with less wheezing. Studies regarding early exposure to pets yielded contradictory results. While some researchers reported a protective feature, other studies suggested removing pets for reducing symptoms of asthma [21-25]. It was proposed that decision to keep a pet at home should not be based on this matter. A systematic review of 47 studies on this subject revealed opposing conclusions probably due to different methods used, various study designs, exposure definition and outcome assessment [26]. Also there may be a threshold for allergen exposure which further complicates any conclusion [27]. Elimination of cats and dogs from house space would have less effect on endotoxin level compared to home cleanliness [28].

In our study, more frequent truck passing was associated with higher wheezing among children. This finding was consistent with other studies [29, 30]. Different air pollutants released from motor vehicles can contribute to increased incidence of asthma and its symptoms such as wheezing [31]. Traffic related pollution may even have higher influence on self-reported wheezing compared to other symptoms [32]. We only asked about place of residence, but location of primary school may have similar effects too. Children breathe more air per weight of their body, consequently exposure to air pollution may have greater effects in childhood [31]. 
The use of a self-report health questionnaire may have affected our findings. Since a considerable discrepancy between parents' and clinicians' reports of asthma is reported in some studies [33]. Nature of asthma is highly complex and wide ranging. Thus, many studies on impact of contributing factors have yielded contradictory results. This study in Yazd province was an opportunity to evaluate the prevalence of asthma and allergies in children with a standard questionnaire and method. Reliance of our study on sole self-reports may be one of the most important limitations of our study. However, this limitation is almost inevitable in this kind of epidemiological studies.

In conclusion, regarding results obtained in our study, school setting can help researchers estimate the prevalence of asthma and associated environmental factors in a certain region. More detailed examination by physician can help establish a definite diagnosis and conduct necessary measures such as exempting asthmatic students of participation in heavy school sports programs. Based on our findings, air pollution can cause more severe asthma symptoms, while keeping cats in household may help reduce wheezing. Possible benefits of recommending keeping a cat at household need further studies. To better understand and confirm the role of specific allergens we recommend conducting longitudinal regional studies. Analyzing trend of prevalence of asthma symptoms and environmental factor can help understand the association.

\section{REFERENCES:}

1. Berry, J.G., et al. Inpatient growth and resource use in 28 children's hospitals: a longitudinal, multiinstitutional study. JAMA Pediatr, 2013. 167(2): p. 170-7.

2. Blume, C. and D.E. Davies, In vitro and ex vivo models of human asthma. Eur J Pharm Biopharm, 2013. 84(2): p. 394-400.

3. Karimi, M., et al., Pregnancy outcomes in asthmatic women. Iranian Journal of Allergy, Asthma and Immunology, 2008. 7(2): 105-106.

4. Holgate, S., et al. The Brussels Declaration: the need for change in asthma management. Eur Respir J, 2008. 32(6): 1433-42.

5. Karimi, M. and M. Mirzaei, Antibiotic use and symptoms of asthma, allergic rhinitis and eczema in children. Iranian Journal of Pediatrics, 2009. 19(2): p. 141-146.

6. Sears, M.R., Trends in the prevalence of asthma. Chest, 2014. 145(2): p. 219-25.

7. Holgate, S.T., et al. A new look at the pathogenesis of asthma. Clin Sci (Lond), 2010. 118(7): 439-50.

8. Patel, S.P., M.R. Jarvelin, and M.P. Little, Systematic review of worldwide variations of the prevalence of wheezing symptoms in children. Environ Health, 2008. 7: p. 57.

9. Pescatore, A.M., et al. "Attacks" or "Whistling": Impact of Questionnaire Wording on Wheeze Prevalence Estimates. PLoS One, 2015. 10(6): e0131618.

10. Asher, M.I., et al. International Study of Asthma and Allergies in Childhood (ISAAC): rationale and methods. Eur Respir J, 1995. 8(3): 483-91.

11. Sistek, D., et al. Predictive value of respiratory symptoms and bronchial hyperresponsiveness to diagnose asthma in New Zealand. Respir Med, 2006. 100(12): 2107-11.

12. Jenkins, M.A., et al. Validation of questionnaire and bronchial hyperresponsiveness against respiratory physician assessment in the diagnosis of asthma. Int J Epidemiol, 1996. 25(3): p. 609-16.

13. Entezari, A., et al. A systematic review of recent asthma symptom surveys in Iranian children. Chron Respir Dis, 2009. 6(2): 109-14. 
14. Stipic-Markovic, A., et al. [Prevalence of symptoms of asthma, allergic rhinitis, conjunctivitis and atopic eczema: ISAAC (International Study of Asthma and Allergies in Childhood) in a population of schoolchildren in Zagreb]. Acta Med Croatica, 2003. 57(4): p. 281-5.

15. Huang, C., et al. Updated prevalences of asthma, allergy, and airway symptoms, and a systematic review of trends over time for childhood asthma in Shanghai, China. PLoS One, 2015. 10(4): p. e0121577.

16. Wieringa, M.H., et al. Gender differences in respiratory, nasal and skin symptoms: 6-7 versus 13-14-year-old children. Acta Paediatr, 1999. 88(2): p. 147-9.

17. Burke, H., et al. Prenatal and passive smoke exposure and incidence of asthma and wheeze: systematic review and meta-analysis. Pediatrics, 2012. 129(4): p. 735-44.

18. Chan-Yeung, M., et al. Early environmental determinants of asthma risk in a high-risk birth cohort. Pediatr Allergy Immunol, 2008. 19(6): p. 482-9.

19. Gaffin, J.M., W. Kanchongkittiphon, and W. Phipatanakul, Perinatal and early childhood environmental factors influencing allergic asthma immunopathogenesis. Int Immunopharmacol, 2014. 22(1): p. 21-30.

20. Carlsen, K.H. and K.C. Lodrup Carlsen, Parental smoking and childhood asthma: clinical implications. Treat Respir Med, 2005. 4(5): p. 337-46.

21. Brunekreef, B., et al. Exposure to cats and dogs, and symptoms of asthma, rhinoconjunctivitis, and eczema. Epidemiology, 2012. 23(5): p. 742-50.

22. Rao, D. and W. Phipatanakul, Impact of environmental controls on childhood asthma. Curr Allergy Asthma Rep, 2011. 11(5): p. 414-20.

23. Salo, P.M. and D.C. Zeldin, Does exposure to cats and dogs decrease the risk of developing allergic sensitization and disease? The Journal of allergy and clinical immunology, 2009. 124(4): p. 751-752.

24. Svanes, C., et al. Do asthma and allergy influence subsequent pet keeping? An analysis of childhood and adulthood. J Allergy Clin Immunol, 2006. 118(3): p. 691-8.

25. Karimi, M., et al. Pet Exposure and the Symptoms of Asthma, Allergic Rhinitis and Eczema in 6-7 Years Old Children. Iranian Journal of Allergy, Asthma and Immunology, 2011. 10(2): p. 123-127.

26. Chen, C.M., et al. The role of cats and dogs in asthma and allergy--a systematic review. Int J Hyg Environ Health, 2010. 213(1): p. 1-31.

27. Chen, C.M., et al. Is there a threshold concentration of cat allergen exposure on respiratory symptoms in adults? PLoS One, 2015. 10(6): p. e0127457.

28. Ownby, D.R., et al. Are Cats and Dogs the Major Source of Endotoxin in Homes? Indoor air, 2013. 23(3): p. 219-226.

29. Brunekreef, B., et al. Self-reported truck traffic on the street of residence and symptoms of asthma and allergic disease: a global relationship in ISAAC phase 3. Environ Health Perspect, 2009. 117(11): p. 1791-8.

30. Karimi, M., et al. Type of fuel consumed and frequency of lorry passing associated with allergic rhinitis and asthma symptoms in children. 2005.

31. Gasana, J., et al. Motor vehicle air pollution and asthma in children: a meta-analysis. Environ Res, 2012. 117: p. 36-45.

32. Ranzi, A., et al. Exposure to air pollution and respiratory symptoms during the first 7 years of life in an Italian birth cohort. Occup Environ Med, 2014. 71(6): p. 430-6.

33. Cane, R.S., S.C. Ranganathan, and S.A. McKenzie, What do parents of wheezy children understand by "wheeze"? Arch Dis Child, 2000. 82(4): p. 327-32.

\section{Corresponding author:}

\section{Mirzaei}

Tehran University of Medical Sciences

Tehran, Iran

e-mail: mojtaba.mirzaei.87@gmail.com 